\title{
WHY IS PRODUCT MODULARITY UNDERDEVELOPED IN CONSTRUCTION?
}

\author{
Cecilia G. da Rocha ${ }^{1}$ and Lauri Koskela ${ }^{2}$
}

\begin{abstract}
Product modularity (a term often associated with off-site construction/prefabrication) has been discussed in construction for a few decades. In spite of that, its understanding in this new context is still emergent. This paper sets out to explore why that is the case. The paper builds on both (i) recent investigations of this concept in construction, including empirical studies which are critically analysed here, and (ii) seminal works on the definition of product modularity in manufacturing. An important insight is that product modularity can benefit traditional construction (by adopting a space-oriented perspective), and thus should not be considered applicable only to off-site construction. Conversely, off-site construction does not ensure per se the adoption of product modularity (even though the terms might be sometimes perceived as closely related). Based on the analysis of literature and empirical cases, three limitations in the understanding and application of product modularity in construction are: (i) unclear boundaries between modules (namely, which components pertain to which module), (ii) invariant modules (namely, the components forming a module do not change depending on the combination in which it is used), and (iii) interfaces as synonymous with surfaces (despite the fact that an interface might entail more than one surface and vice-versa).
\end{abstract}

\section{KEYWORDS}

Modular construction, interfaces, customisation, off-site construction.

\section{INTRODUCTION}

Product modularity (or modular architecture) has been extensively researched and applied in manufacturing but has not received the same attention in construction. In the last two decades, some studies (Schmidt et al. 2011, Björnfot and Stehn 2004; Lennartsson et al. 2009; Jensen et al. 2014; Wikberg and Ekholm 2011) set out to adapt methods for modularization in construction based on tools adopted in manufacturing such as Design Structure Matrix, Function, Heuristics, Design for Variety, etc. (Kohl et al. 2017). Despite such initiatives, a conceptual understanding of modules and key underpinnings (functional elements, physical components, interfaces, etc.) for the construction context is still required. A recent example of the lack of clear and common understanding is provided, for instance, by Gosling et al. (2016). The referred authors carried out a survey

1 Lecturer, School of Civil and Environmental Engineering, University of Technology Sydney (UTS), City Campus, Broadway, Bldg 11, Lv 11, NSW 2007, Australia, cecilia.rocha@uts.edu.au, doi.org/0000-0001-6764-1724

2 Professor, School of Art, Design and Architecture, University of Huddersfield, Queen Street Building, Queen St., Huddersfield, West Yorkshire, HD1 3DU, United Kingdom, L.Koskela@hud.ac.uk, 0000doi.org/0003-4449-2281 
in fifteen construction projects to identify what people understood as a module. This concept was equated to different building parts ranging from concrete mix to volumetric pods, suggesting that so far, there has not been common understanding on the meaning of the term "module" in construction.

Efforts have also been made to explore the differences between construction and manufacturing in regard to modularity (e.g., Kohl et al. 2017, Rocha et al. 2015). Yet, comprehensive discussions with a clear logical reasoning of why and how product modularity is affected by each particular difference are still needed. This paper explores two of such differences. First, buildings are formed by spatial voids in addition to physical components (e.g., pillars, beams, ceilings, fixtures, tiles, etc), whereas the majority of manufacturing products only involve physical components (Rocha et al. 2015). Thus, product modularity in buildings can be considered in terms of two perspectives (Rocha et al. 2015): space or component-oriented. Second, a further characteristic of construction is that products (buildings) are largely one-off products (Vrijhoef and Koskela 2000). As a result, the particular set of modules used for a building is usually also a one-off and thus unlikely to be used to construct another building (da Rocha and Kemmer 2018). Differently, the same set of modules is used to produce a large number of identical manufacturing products. In addition, usually modules have a single meaning for each manufacturing product (e.g., all cars are formed by a cockpit, a chassis, etc.). This is opposite to construction where the meaning varies: a module might be a pod in one building and a brick in another. This helps to explain the multiple understandings of modules identified by Gosling et al. (2016) and also why the concept of module is unclear in the construction context.

By exploring these differences and the key underpinnings of product modularity, a theoretical analysis of modules in construction is undertaken in this paper. The underpinnings examined here were proposed Ulrich 1995): a seminal and widely referenced paper for product modularity (3842 citations in Google Scholar on May 11, 2020). More specifically, the aim is (i) to graphically show these underpinnings in practical/real construction project cases and (ii) to detail the difficulties (at a technical level) in applying product modularity in such context. In order to do that, two projects studied by the first author of this paper and fellow co-authors reported in previous publications (da Rocha and Kemmer 2018, da Rocha and Kemmer 2013, and Gravina da Rocha et al. 2019) are compared here. These empirical cases, both housing projects, involve two distinct construction methods, namely, in situ cast reinforced concrete and prefabricated timber panels.

\section{WHAT IS A MODULE?}

\section{Partitioning Rationale And Levels}

The concept of "module" arises from the notion that (i) a product can be partitioned into chunks (i.e. the modules) or that (ii) the physical units forming a product can be grouped into chunks (e.g., Baldwin and Clark 1997, Fixson 2005, Salvador 2007). In addition, such partitioning/grouping can be applied at distinct product levels, also known as hierarchical product breakdown (Figure 1). That is, a product can be partitioned into chunks, such chunks into sub-chunks, and so on and so forth. As a result, (i) level(s) can be considered when looking at product modularity and (ii) distinct partitioning or grouping can be created at each particular level. The (i) levels and (ii) partitioning or grouping rationales (namely, why a product will be formed by a particular set of chunks) 
to be considered are dependent on the goals for product modularity (Pandremenos et al. 2009, Sako and Murray 1999). Such goals can include the provision of product variety, production simplification, outsourcing of product parts, among others.

For example, if the goal is to simplify production (by reducing the number of parts), the viewpoint is that of the construction site, and the modules are the physical parts arriving there to erect a building. Such physical parts (or modules) can range from small elements such as brick, paint, and nails to volumetric pods, depending on the construction methods used (da Rocha and Kemmer 2019; Gosling et al. 2016). Likewise, if the goal is to provide product variety while allowing for production efficiency, the partitioning rationale should focus on creating a large module (or platform) combining all functions and related components, for which clients do not require variety. The other functions and components, for which client requirements diverge, should be allocated to distinct modules that can be added to the platform.

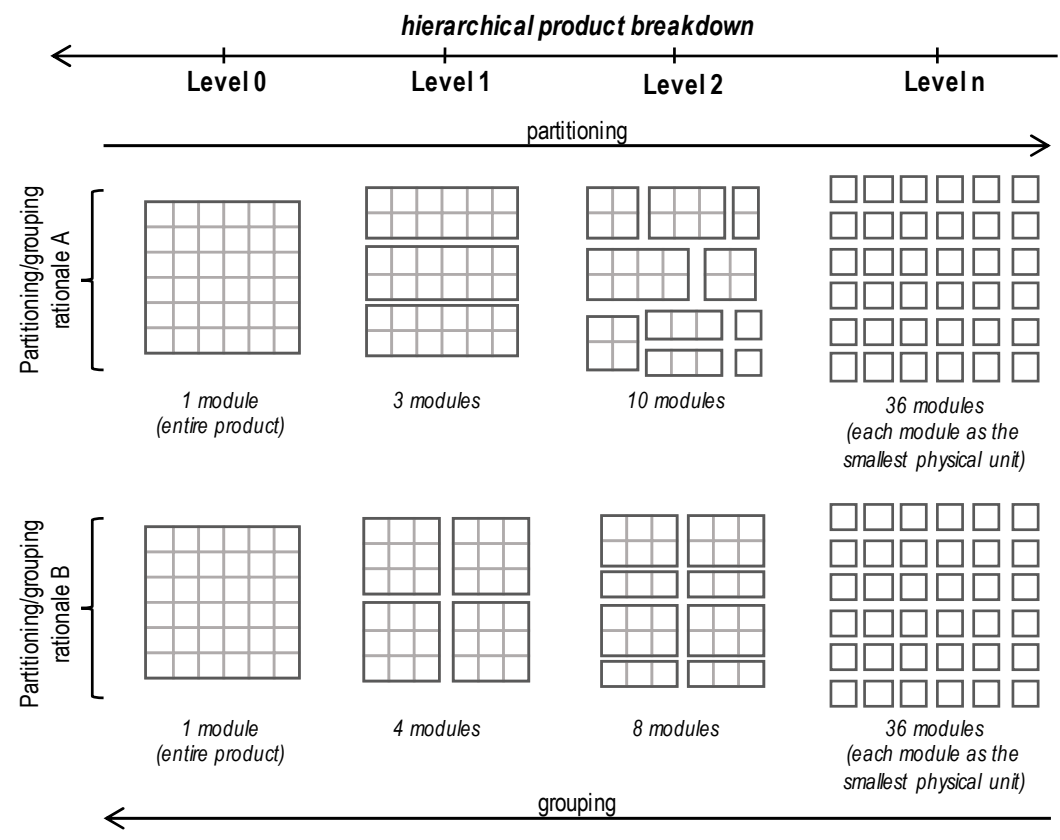

Figure 1: Levels of product modularity and partitioning rationales

Two related notions (albeit not always applicable) are that (iii) the chunks forming a product can be mixed and matched and (iv) as the possible combinations among modules increase, so does the modularity degree. Thus, a system of products or product variants (namely, the products created by combining the modules) instead of a single product is the appropriate unit for product modularity (Salvador 2007). These two additional notions might not be always relevant as they depend on the goal considered for product modularity. For example, they are central if product variety is targeted since the number of product variants (or variety level) are directly associated to the number of possible combinations. Yet, they are not essential if product modularity is adopted to partition the product into chunks that can be independently developed by distinct design teams.

\section{Primary AND SECONDARY FunCtions}

The understanding of modules proposed by Ulrich (1995) implies that product modularity involves (i) the allocation of functional elements into physical components (or modules) (ii) the definition of the interfaces between such components (this second aspect is 
discussed in the following section). The relationship between functional elements and physical components (or physical units) is essential to determine the product architecture type (Ulrich 1995). Modular architectures are defined by a one-to-one allocation scheme between functions and physical components (Ulrich, 1995), implying that each module is independent in the sense that it performs only one function. Differently, integral architectures are defined by many-to-one or many-to-many allocation schemes. These allocations do not allow modules to be easily mixed and matched since the product is not designed/organized as a set of individual chunks but mainly as a disordered/bundled set of functions and components.

A number of studies (e.g., Stone et al. 2000, Fixson 2007) illustrate what is understood as functional elements and physical components within the manufacturing domain. For instance, functional elements for an electrical screwdriver include: supply electricity, store electricity, convert electricity to torque, rotate solid, etc. (Stone et al. 2000), whereas the physical components can include wire, bolts, nuts, pins, bit holder, switch, etc. Equally important is the notion that both the functional elements and physical components can be considered at distinct product levels (Fixson 2007). As exemplified by the cited author, at the highest level (i.e. having the entire product as a module) the function of a hair dryer is to dry the hair. Differently, at the lowest level (i.e. having the smallest component such as a screw as a module), the function might be just hold two parts attached. These two instances (highest and lowest levels) are illustrated by level 0 and level $n$ in Figure 1.

Considering Vermaas' (2010) conceptualization of functions (goal, action, function, behaviour, and structure of devices) and five models, product modularity is aligned with function as a bypassing concept model. In such model, the focus is on the connection among goals of the devices (e.g., illuminate a room for a lamp product), the functions of the device (e.g., electricity converted into light), and the structure of the device (e.g., glass bulb containing a wire in vacuum) (Vermaas 2010). The two latter notions can be equated to functional elements and physical components. However, the five levels presented by Vermaas appear to address the product as a whole rather than the chunks (discussed in the previous section) which are the units of interest for product modularity. Indeed, the concept of function (functions of the device according to Vermaas) is relevant from a modularity viewpoint in the sense that the level considered for the hierarchical breakdown should be between the function performed by the entire product and the function performed by its smallest physical part.

Buildings differ from manufacturing products in terms of functional elements, and consequently the relationship between such elements and the physical components. The raison d'être of buildings is to provide spaces for people to perform activities such as reading, sleeping, cooking, resting, working, etc. (Rocha et al. 2015). This is fundamentally different from manufacturing products in which (i) functions are performed by components (physical mass) rather than people and (ii) spatial voids are usually non-existing. (Clearly, it can be argued that some manufacturing products such as cars, trucks, airplanes, etc., have spatial voids but the number, scale, and complexity of such voids is not comparable to the ones encountered in buildings). The activities performed by people have been termed by Rocha et al. (2015) as primary functions to distinguish them from secondary functions which are performed by physical components similar to manufactured products. Such secondary functions can include insulation against thermal flows and noise, wind and water shielding, allowing or preventing visibility, etc. Indeed, in order (i) for the spatial voids to exists and/or (ii) for the primary 
functions to be comfortably carried out, components in the form of building systems are needed (Rocha et al. 2015).

\section{Primary or Secondary functions in Definition of Modules}

Considering the notion of primary and secondary functions, product modularity can be considered in terms of two perspectives as discussed in Rocha et al. (2015). The first one looks at secondary functions performed by physical components (component-oriented perspective), similar to product modularity as adopted in manufacturing. The second one (which will be further explored in this paper) looks as primary functions and the spatial voids and enclosing components that create such voids, which is specific to buildings. The notion of modules containing spatial voids and the components creating such voids might be associated to volumetric pods produced off-site. However, this is not necessarily the case: a building can be designed to be comprised by modules containing spatial voids and be built using traditional construction method (e.g., in situ cast reinforced concrete and bricks and blocks masonry) as the building illustrated in Figure 2.

Indeed, a study detailing the benefits of designing modules in terms of spatial voids for traditionally built projects, particularly when adopting Delayed Product Differentiation (DPD), was performed by da Rocha and Kemmer (2013). The examined building is, from a modularity viewpoint, formed by (i) a platform, a number of spaces (marked in white in Figure 2) such as kitchen, laundry, living room, and their enclosing components such as walls, ceilings, windows, services systems, etc, and (ii) four families of modules (A, B, C, and D). The rationale under DPD is to produce the platform (including all fixtures and finishing) and later build a module from each of the families according to the interior layout selected by the client. Organizing the apartment production in these two batches (rather than in one single batch) postponed the Decoupling Point (DP), namely, the moment in which the clients' decisions are needed to perform construction tasks, from week 1 to week 42 in the production schedule totalling 138 weeks. Thus, production is shielded from variations due to customisation (variation of the product itself and variability in the timing of clients' input) in 30\% (42/138) of the production time.

\section{WHAT IS AN INTERFACE?}

\section{INTERFACES AND FAMILIES OF MODULES}

Regardless if modules are (i) sub-assemblies produced off-site or (ii) fabricated on the construction site [as the apartment project examined in (da Rocha and Kemmer 2013, 2018)], how they are connected is a key issue, which is conceptualized as interface (or modules interface) in the product modularity literature. In some studies (e.g., Ulrich 1995, Sanchez 1995, Schilling 2000), an interface is characterized as coupled or tightly coupled (for integral architectures) or decoupled or loosely coupled (for modular architectures). This provides a notion that modules can be easily detached and re-combined in modular architectures (but not in integral ones). Other studies (e.g., Salvador et al. 2002, Pine 1999) explore the notions of (i) interface types and (ii) families of modules. A good example is the USB and jack ports (Figure 3): two interface types for connecting modules such as keyboards, external hard drives, etc., to a computer. All devices that have a USB port (e.g., mouse, keyboard, etc.) can be understood as a family of modules as they can be connected to another module (i.e. the computer) via the same interface type. The same applies for devices with the jack port: they form another family of modules. 


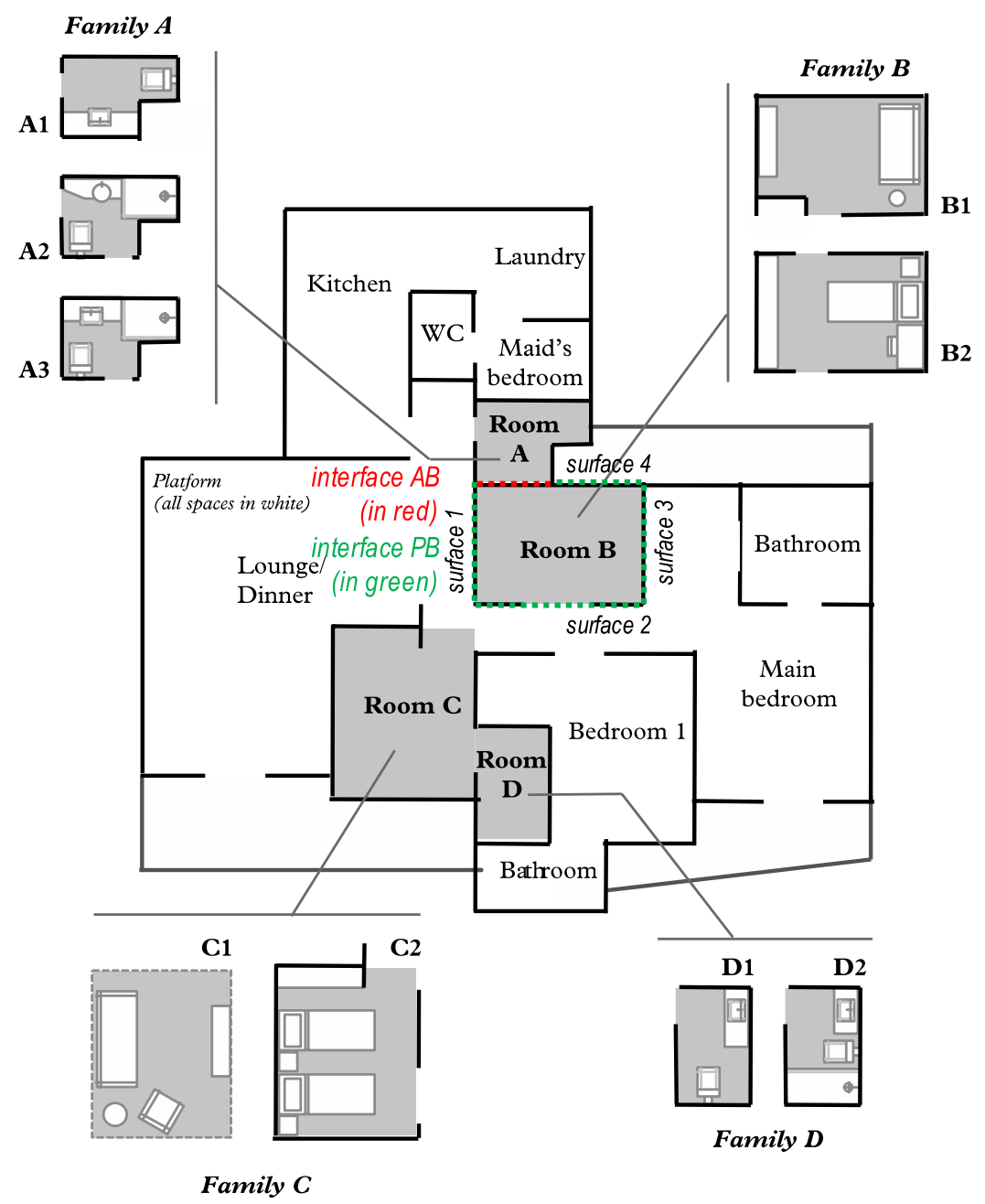

Figure 2: Traditionally constructed building with modules (platform and families A, B, C and D) containing spatial voids (adapted from da Rocha and Kemmer 2018)

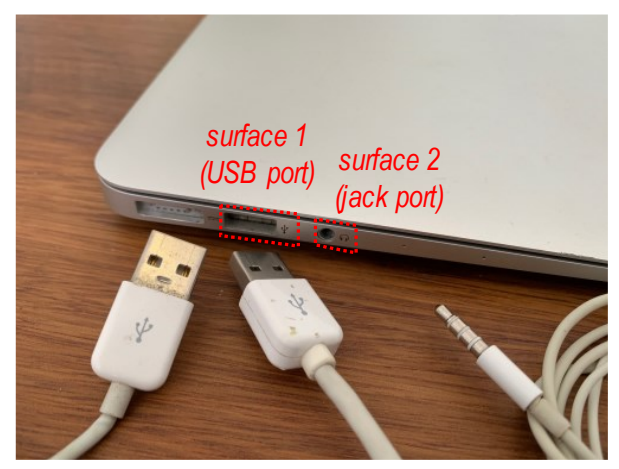

Figure 3: USB and jack ports

Using these two notions (e.g., family of modules and interface types), some taxonomies (e.g., Salvador et al. 2002, Pine 1999, Ulrich 1995) have been proposed. Although they are more advanced in comparision to the notions of decoupled/coupled and loosely/tightly coupled, they still do not provide sufficient technical detail regarding the connection between each pair of modules. Pimmler and Eppinger (1994) shed some light by suggesting four types of interactions between modules: (i) spatial interactions (i.e., 
requirement for adjacency or orientation), (ii) energy interactions (i.e., requirement for energy transfer), (iii) information interactions (i.e., requirement for information exchange), and (iv) material interactions (i.e., requirement for material exchange). All of these apply to buildings products considering that these involve electrical systems (energy transfer), data systems (information transfer), and HVAC systems (material transfer such as air or water). In addition, other interactions also apply such as loads and stress interactions (among the components forming the structural system).

Nonetheless, spatial interactions are still the most fundamental relationship: every module needs to have a particular form and geometrical position (considering a threedimensional grid) in the building and in relationship to other modules. Appropriate spatial interactions are also necessary for other interactions to properly take place (Rocha et al. 2015): sink and pipe need to be geometrically aligned for the water to flow. Likewise, structural elements need to be spatially coordinated for stress to be adequately transferred. Yet, it is important to observe that two modules can have a spatial interaction without having any physical connection (e.g., they need to be at a particular distance from each other). Outlining (i) the types of interaction between every two modules and (ii) the accepted levels for each interaction type is essential for understanding the technical implications of combining distinct modules.

\section{PROBLEMS IN INTERFACES DEFINITION}

The construction sector is still lagging regarding the conceptualizations discussed here, particularly regarding interfaces. Consider the two following examples: Project $\mathrm{J}$ examined in (da Rocha and Kemmer 2013, 2018) for traditional construction (Figure 2) and the ZEMCH housing project investigated in (Gravina da Rocha et al. 2019) for offsite construction (Figure 4). The interface between families of modules A and B (termed as interface $\mathrm{AB}$ ) changes depending on the modules used (Figure 2). For instance, if modules A2 or A3 are combined with module B2, the interface entails a wall with a door. Differently, if module A1 is combined with module B1, the related interface is only a wall (with no door). In addition, it is not clear if such a wall (and the components forming it) pertains to the modules from family A (A1, A2, or A3) or family B (B1 or B2). Thus, two interrelated problems can be observed here: (i) unclear boundaries between modules and (ii) modules that are not invariant, namely, involve adjustments in physical components (i.e. door) forming each module change depending on the combination in which they are used in.

The same problems can also be observed in the off-site project (Figure 4). If the platform (spatial voids such as living/dining, kitchen, etc., and the components enclosing such voids, marked in green in Figure 4) is combined with a garage (module C1), the interface PC (Platform-family C) is a wall. Differently, if the platform is combined with a bedroom (module $\mathrm{C} 2$ ), the respective interface changes to a wall with a door. Here too it is not clear if the wall (with or without the door) belongs to the platform or to the modules from family $\mathrm{C}$ (module $\mathrm{C} 1$ or $\mathrm{C} 2$ ). This also applies to the interfaces $\mathrm{PA}$ and $\mathrm{PB}$, between platform and Family A (Bathroom A1, marked in blue) and between platform and Family B (Laundry B1, marked in yellow), respectively. Indeed, when the platform is used in isolation (without any modules from families $\mathrm{A}, \mathrm{B}$, or $\mathrm{C}$ ), the interfaces (PA, $\mathrm{PB}$, and $\mathrm{PC}$ ) are only walls whereas doors need to be added if modules are to be attached. 

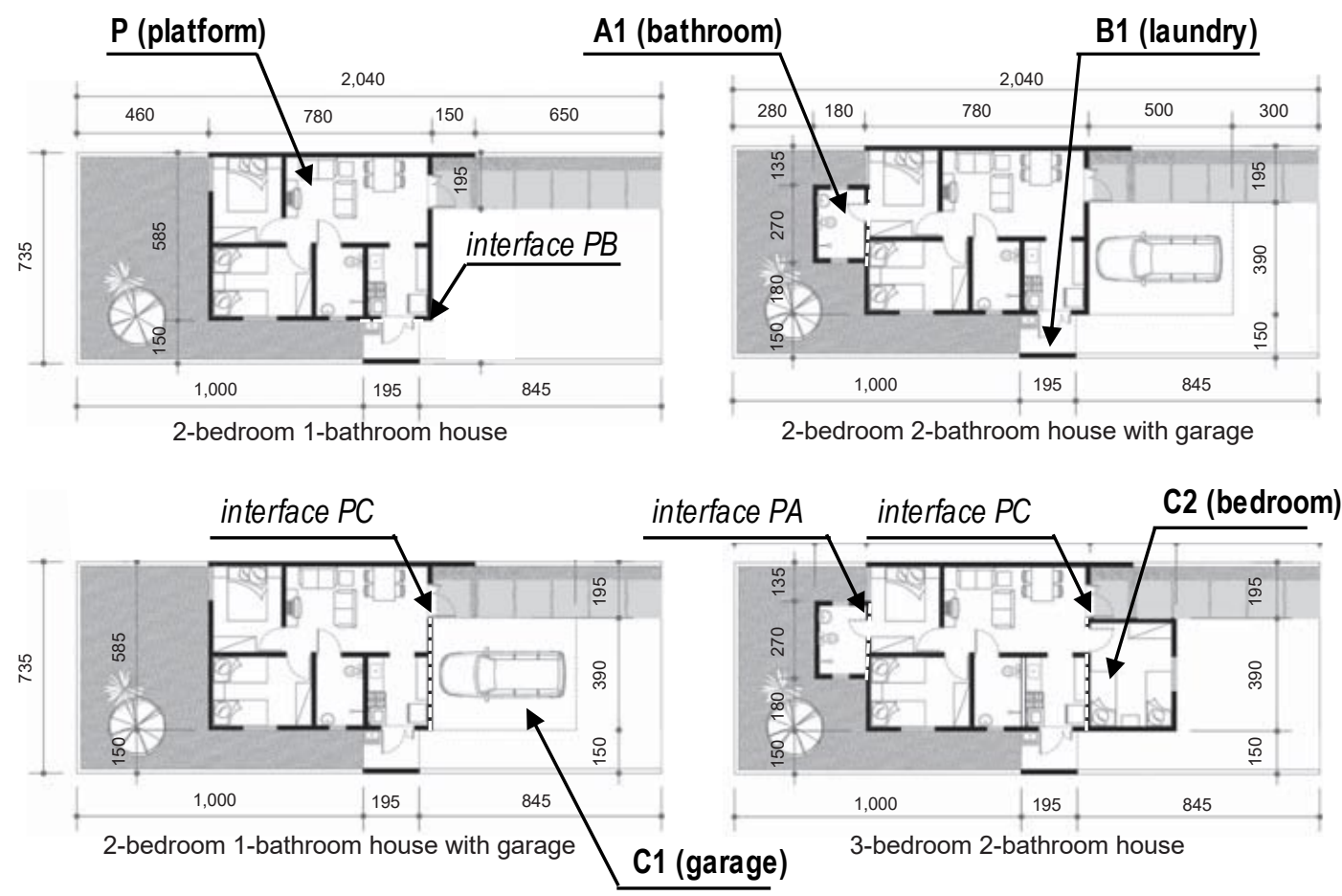

Figure 4: Example of interface problems in off-site construction (adapted from Gravina da Rocha et al. 2019)

The changes in components forming each module is against the logic of product modularity, particularly when the goal is to efficiently provide product variety by mixing and matching standard chunks. If modules need to be altered, such efficiency is lost or at least reduced. It is proposed here that the problems in the interface definition are due to spatial voids. Modules containing spatial voids will most likely be formed by at least six surfaces, considering a spatial void to be a cuboid. (Clearly, spatial voids with more complex geometries such as the L-shaped Bedroom 1 in Figure 2 can occur, further increasing the number of surfaces). This can result in six interfaces, in case each of the surfaces is connected to a different module. Conversely, modules in manufactured products do not (usually) entail spatial voids and thus are likely to have a smaller number of surfaces. For instance, the USB or jack phone involve only one surface (marked in red in Figure 3) to connect a module (e.g., headphone, mouse) to another module (e.g., the computer), differently from a module like room B in Figure 2, which has six surfaces potentially interacting with other modules.

Yet, it is important to clarify the difference between interfaces and surfaces: a cuboid has six surfaces which might translate into six interfaces, but only when each surface is connected to a different module. However, (i) a single interface might involve more than one surface and (ii) a surface might be part in two or more interfaces. An example is Room B in Figure 2, which has three surfaces or walls "touching" the Platform (thus a single interface) but also a wall (surface 4) containing two interfaces: between Room A and Room B (interface $\mathrm{AB}$ ) and between Platform and Room B (Interface PB). Examining the surfaces forming each interface is important for understanding the details and technicalities of connecting each pair of modules, despite the fact that from a conceptual perspective (i.e. from a modularity viewpoint) they are still understood as a single interface. The fact that interfaces in manufactured products appear to be simpler 
(as discussed for the USB port) might explain the lack of distinction between interface or surface (or having interface as a synonym for a single surface) in the literature.

\section{CONCLUSIONS}

This paper aims at creating a deeper theoretical understanding of product modularity in construction and its peculiarities in comparison to manufacturing. In order to do that, key underpinnings were reviewed and discussed considering two characteristics of construction, namely spatial voids and one-off products, which affect the application of product modularity in this context. In addition, two empirical studies were presented to illustrate in more detail what is a module in a space-oriented perspective, which is specific to building products. These studies were also used to show practical instances of the problems in applying modularity in construction, especially regarding the definition of modules' interfaces. However, this paper is limited to (i) discussing only a few interfaces (and not all interfaces for all combinations of modules) and (ii) being based on a few architectural drawings (rather than the complete information package required for a project), both of which are needed for a comprehensive assessment of product modularity.

It is argued that the space-oriented perspective is more appropriate in construction than the component-oriented perspective due to three reasons. First, having spaces as the focal unit is more aligned with the nature or raison d'être of buildings rather than focusing on the physical mass or components forming spaces. Second, from a value viewpoint, the client (dweller or user) requirements are more likely to be expressed or structured in terms of the spaces forming a building: having a bedroom removed to enlarge the living room, having a specific tiling for a bathroom, etc. (This paper does not otherwise discuss the role of product modularity for value, which can be explored in further studies). Clearly, adopting a space-oriented perspective still require the components enclosing such spaces (and which create the interfaces between the modules) to be considered and organized from a modularity viewpoint. However, such organization should subscribe to the spaceoriented perspective since only focusing on the components is likely to preclude the benefits of a space-oriented perspective to be achieved.

Third, the component-oriented perspective is prone to local optimization since the attention will most likely be directed on only one or a few building systems at a time rather than the building as a whole. Differently, the space-oriented perspective, being structured in terms of the spaces forming a building (and the supporting physical parts), is more likely to support global optimization for improving project performance (variety, simplification, delivery time, cost, etc.). Thus, it is suggested that such a perspective is more compatible with the lean tenets. Fourth, looking at modularity from a space-oriented perspective allows this concept to also be applicable and create benefits to traditional construction as illustrated by the high-rise building project examined here (Figure 2). In such a case, the alignment between the modules and work packages/work structure (e.g., Ballard 1999, Tsao 2005, Tsao et al. 2000) as detailed in (da Rocha and Kemmer 2018) is central.

Indeed, studies on modularization methods in construction appear to either (i) adopt a component-based perspective or (ii) not clearly address the space-oriented perspective. Examples of the first group include Björnfot and Stehn (2004), Lennartsson et al. (2009) Mohamad et al. (2014), and Mohamad et al. (2013), where the method was applied to a particular set of components such as service systems or the structural system (rather than the building as a whole). Examples of the second group include Veenstra et al. (2006) and Wikberg and Ekholm (2011), which propose a technical platform, but it is unclear 
whether such platforms encompass spaces or not. As for the question presented in the title of this paper, our conclusion is that the use of a less appropriate conceptualization of modularity (namely, component-oriented) has been a major reason for its lack of development (and application) in construction. Indeed, (i) the one-off nature of construction, which results in multiple meanings for the term "module", and (ii) the spatial voids forming a building, which leads to the interface problems discussed here, are two conceptual considerations that are missing for a more adequate understanding of modularity in this context. Clearly, this does not preclude other reasons from contributing to this underdevelopment.

In terms of future research, it is important for upcoming studies to acknowledge the multiple meanings of modules in construction and, based on that, to clearly outline what are the modules and their components (if possible, not only with text but also with drawings and diagrams) in the particular projects investigated. Another important research endeavour is to engage with design and construction teams adopting a spaceoriented perspective (like the two cases presented) and discuss the interface problems identified here: (i) why changes in the components forming a module are required depending on the combination in which this module is used in, and (ii) what would be the challenges of having truly invariants modules. Such discussion can assist in further understanding this problem in addition to potential ways to overcome it.

\section{REFERENCES}

Baldwin, C. Y., and Clark, K. B. (1997). "Managing in an age of modularity." Harvard Business Review, 75(5), 84-93.

Ballard, G. (1999). "Work structuring." White Paper, 5.

Björnfot, A., and Stehn, L. (2004). "Industrialization of Construction -a Lean Modular Approach." 12th Annual Conference of the International Group for Lean Construction, S. Bertelsen and C. T. Formoso, eds., Helsingør, Denmark.

Fixson, S. K. (2005). "Product architecture assessment: a tool to link product, process, and supply chain design decisions." Journal of Operations Management, 23(3-4), 345-369.

Gosling, J., Pero, M., Schoenwitz, M., Towill, D., and Cigolini, R. (2016). "Defining and Categorizing Modules in Building Projects: An International Perspective." Journal of Construction Engineering and Management, 142(11), 04016062.

Gravina da Rocha, C., El Ghoz, H. B. C., and Jr Guadanhim, S. (2019). "A model for implementing product modularity in buildings design." Engineering, Construction and Architectural Management, Vol. 27 No. 3, pp. 680699. https://doi.org/10.1108/ECAM-02-2019-0096.

Jensen, P., Olofsson, T., Smiding, E., and Gerth, R. (2014). "Developing Products in Product Platforms in the AEC Industry." Computing in Civil and Building Engineering (2014), American Society of Civil Engineers, Orlando, Florida, United States, 1062-1069.

Kohl, M., Wilberg, J., Tommelein, I., Pikas, E., and Lindemann, U. (2017). "Modularization: Exploring opportunities for knowledge transfer between the mechanical engineering and construction industry." 21st International Conference on Engineering Design (ICED17), Vol. 6: Design Information and Knowledge, Vancouver, Canada. 
Lennartsson, M., Bjronfot, A., and Stehn, L. (2009). "Production Control Through Modularisation." 17th Annual Conference of the International Group for Lean Construction, Y. Cuperus and E. H. Hirota, eds., Taipei, Taiwan, 453-464.

Mohamad, A., Gehbauer, F., and Haghsheno, S. (2014). "Improving the Implementation of Modularization and Standardization of MEP Systems in Design." 22nd Annual Conference of the International Group for Lean Construction, B. T. Kalsaas, L. Koskela, and T. A. Saurin, eds., Oslo, Norway, 509-518.

Mohamad, A., Hickethier, G., Hovestadt, V., and Gehbauer, F. (2013). "Use of Modularization in Design as a Strategy to Reduce Component Variety "in" missing here? One-Off Projects." 21 th Annual Conference of the International Group for Lean Construction, C. T. Formoso and P. Tzortzopoulos, eds., Fortaleza, Brazil, 289-298.

Pandremenos, J., Paralikas, J., Salonitis, K., and Chryssolouris, G. (2009). "Modularity concepts for the automotive industry: A critical review." CIRP Journal of Manufacturing Science and Technology, 1(3), 148-152.

Pine, B. J. (1999). Mass customization: the new frontier in business competition. Harvard Business School Press, Boston, Mass.

Rocha, C., Formoso, C., and Tzortzopoulos, P. (2015). "Adopting Product Modularity in House Building to Support Mass Customisation.” Sustainability, 7(5), 4919-4937.

da Rocha, C. G., and Kemmer, S. (2018). "Integrating product and process design in construction." Construction Management and Economics, 36(9), 535-543.

da Rocha, C. G., and Kemmer, S. L. (2013). "Method to Implement Delayed Product Differentiation in Construction of High-Rise Apartment Building Projects." Journal of Construction Engineering and Management, 139(10), 05013001.

Sako, M., and Murray, F. (1999). "Modules in design, production, and use: Implications for the global automobile industry." MIT IMVP Annual Sponsors Meeting, Cambridge.

Salvador, F. (2007). "Toward a Product System Modularity Construct: Literature Review and Reconceptualization." IEEE Transactions on Engineering Management, 54(2), 219-240.

Salvador, F., Forza, C., and Rungtusanatham, M. (2002). "How to mass customize: Product architectures, sourcing configurations." Business Horizons, 45(4), 61-69.

Sanchez, R. (1995). "Strategic Flexibility in Product Competition." Strategic Management Journal, 16, 135-159.

Schilling, M. A. (2000). "Toward a General Modular Systems Theory and Its Application to Interfirm Product Modularity." Academy of Management Review, 25(2), 312-334.

Schmidt, R., Deamer, J., and Austin, S. (2011). "Understanding adaptability through layer dependencies." ICED 11 - 18th International Conference on Engineering Design Impacting Society Through Engineering Design, 10.

Stone, R. B., Wood, K. L., and Crawford, R. H. (2000). "A heuristic method for identifying modules for product architectures." Design Studies, 21(1), 5-31.

Tsao, C. C. Y. (2005). "Use of Work Structuring to Increase Performance of ProjectBased Production Systems." University of California Berkeley, Berkeley.

Tsao, C. C. Y., Tommelein, I. D., Swanlund, E., and Howell, G. A. (2000). "Case Study for Work Structuring: Installation of Metal Door Frames." 8th Annual Conference of the International Group for Lean Construction, Brigthon, UK.

Ulrich, K. (1995). "The role of product architecture in the manufacturing firm." Research Policy, 24(3), 419-440. 
Veenstra, V. S., Halman, J. I. M., and Voordijk, J. T. (2006). "A methodology for developing product platforms in the specific setting of the housebuilding industry." Research in Engineering Design, 17(3), 157-173.

Vermaas, P. E. (2010). "Technical functions: Towards accepting different engineering meanings with one overall account." Proceedings of the 8th International Symposium on Tools and Methods of Competitive Engineering, TMCE 2010, 1, 183-194.

Vrijhoef, R., and Koskela, L. (2000). "The four roles of supply chain management in construction." European Journal of Purchasing \& Supply Management, 6(3-4), 169178.

Wikberg, F., and Ekholm, A. (2011). "Design Configuration with Architectural Objects." eCAADe Conference Proceedings, 451-460. 